\title{
Buoyancy model for Guanay II AUV
}

\author{
I. Masmitjà, J. González, S. Gomáriz \\ SARTI Research Group. Electronics Department. Universitat Politècnica de Catalunya. \\ Rambla de l'Exposició, 61-69. Neapolis Building. 08800 Vilanova i la Geltrú. Barcelona. Spain.
}

\begin{abstract}
The AUV Guanay II is a vehicle developed by SARTI research group of Universitat Politècnica de Catalunya with the objective of providing a platform for measuring oceanographic variables, such as the temperature and salinity of the water column. In the vertical dive is important not to disturb the environment to avoid influencing in the measurements. For this reason a variable buoyancy (VB) system to do the vertical immersions has been designed. This paper presents the model designed to change the buoyancy of the vehicle and the tests both laboratory and field.
\end{abstract}

Keywords-Buoyancy; engine-piston; AUV; Guanay II

\section{INTRODUCTION}

The Guanay II [1] [2] [4] [5] [6] is an autonomous underwater vehicle developed by SARTI group of Technical University of Catalonia with the objective of providing a platform for measuring oceanographic variables, such as the temperature and salinity of the water column, with a high simultaneously spatial and temporal resolution.

The underwater vehicles can be classified in different ways. One of this ways is according to their propulsion system. For example: a ROV use multiple propellers to control their position; a Glider uses the variations in their buoyancy and their large fins to move; finally, an AUV can use a single or multiple propellers for propulsion. Nowadays, multiples combinations of these propulsion systems can be exist in one vehicle. For example: Girona500 [7] developed in University of Girona is an AUV with multiple propellers like a ROV; and Tethys [8] a long-range AUV developed in MBARI incorporating a variable buoyancy system, like a Glider, allows the vehicle to be ballasted to drift at depth without consumption.

The Guanay II uses the variable buoyancy system to do the immersions. It navigates over the surface to reach until waypoints, where it stops and dives vertically in a horizontal position (as in the figure 1 can be seen) in order to obtain a profile of a water column (upper water column). A payload of $4 \mathrm{~kg}$ for different sensors, like a CTD or a water quality probe, for the record of important data in the marine environment can be carry. The immersion is done by changes in the vehicle buoyancy (variable buoyancy, VB) through a cylinder that can take and eject 1.5 liters of water.

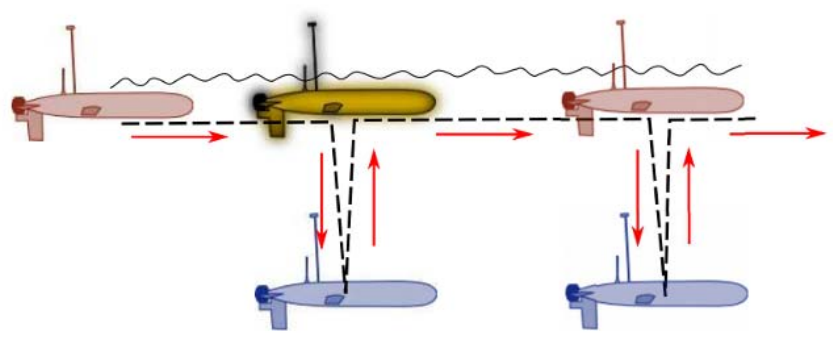

Fig. 1. The Guanay II-AUV motion

This immersion system has been adopted due two important reasons. The first reason is because it is recommendable take measures without to generate perturbations in the environment. The propellers would provoke perturbations

. The second reason is because it has a lower energy cost. The use of a vertical propeller would imply a high current consumption, while cylinder doesn't.

This paper presents the model designed to change the buoyancy of the vehicle and the tests both laboratory and field.

\section{BUOYANCY SYSTEM}

The VB [9] of Guanay II is performed using an enginepiston set (Figure 2). This system is able to collect and eject 1.5 liters of water. The piston is made of stainless steel and has a plunger of a radius of $100 \mathrm{~mm}$ and a path length of 200 $\mathrm{mm}$.

This system is located inside of the sealed cylinder and the water is collected through a connector on one of the covers. When the cylinder is empty (steady state) the vehicle has a neutral buoyancy $(\Delta \mathrm{W}=0)$ equation 1 . When increases the water in the cylinder increases the weight $(\Delta \mathrm{W}>0)$ causing that the force of gravity is greater than the buoyancy force of the vehicle. Then it makes the immersion.

$$
\Delta W=\text { weight }_{\text {vehicle }}-\text { volume }_{\text {vehicle }} \times \text { density }_{\text {water }}
$$




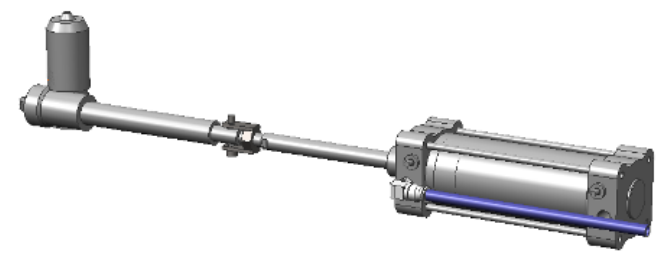

Fig. 2. The Guanay II AUV Engine-piston set for VB system

On the other hand, equation (2) relates the force generated in the piston according to the surface of the piston plunger and the pressure being applied.

$$
F=p \times A
$$

Where: $\mathrm{p}$ is the pressure in $\mathrm{N} / \mathrm{mm}^{2}$; and $\mathrm{A}$ is the area of the cylinder plunger in $\mathrm{mm}^{2}$. Using this equation and knowing that 1 bar $=0.1 \mathrm{~N} / \mathrm{mm}^{2}$ the results of Table 1 has been obtained where the force generated in the piston is related according to the depth.

TABLE I. RELATIONSHIP BETWEEN PRESSURE AND FORCE VS. DEPTH AND CURRENT OF THE ENGINE-PISTON SET

\begin{tabular}{cc|cc}
\hline Pressure (Bar) & Depth (m) & Force (N) & Current (A) \\
\hline 1 & 10 & 785.4 & 3.09 \\
2 & 20 & 1570.8 & 5.19 \\
3 & 30 & 2356.2 & 7.29 \\
4 & 40 & 3141.6 & 9.38 \\
\hline
\end{tabular}

The current shown in table 1 is given by the manufacturer according to the following equation (3).

$$
\text { Current }=\text { Force } \times 0.00267+1
$$

In table 1 the current required is higher when the pressure is high than when the pressure is low as can be seen. Therefore, the vehicle need more power to go up when the depth is highest. But the energy to go down and to do the immersion is always the same and least than the energy to go up. An air chamber has been designed to compensate this situation. The idea is accumulate energy in the immersion action and use this energy to help in the going up of the vehicle. This system uses less energy from the batteries in the going up, for this reason, a greater security is obtained.

\section{AIR CHAMBER}

Moreover, most of the power required is to empty the piston. When the vehicle gets positively buoyant and rises to the surface. This is an inconvenient for safety (vehicle might not have enough energy to go up). For this reason,

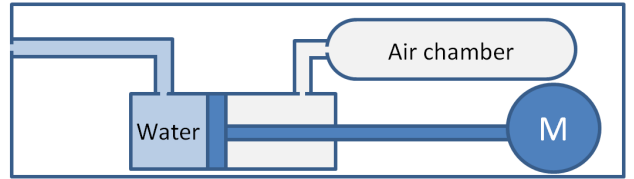

Fig. 3. Block diagram of compensation system of the piston. Picture shows the water entry in the first part of piston and an air chamber in the other hand.

compensation system between the energy required going down and the energy required to going up has been designed.

In Figure 3 a diagram of this system can be seen. When the piston takes water, the air of the other side is compressed in an air chamber. This energy is used to help the piston to do the opposite action.

Using a simple equation of relation between volumes and pressure (4) the amount of energy stored in bars has been obtained. Further, knowing that Volume $=\Pi \mathrm{x} \mathrm{r}^{2} \mathrm{x}$ L, there are the possibility to adjust the dimensions of the air chamber to obtain a desired pressure. In the first prototype a standard PVC pipe of $1.33 \mathrm{~cm}$ radius and $65 \mathrm{~cm}$ long has been used to obtain around 4 bars.

$$
P_{2}=P_{1} \frac{V_{1}}{V_{2}}
$$

Where: $V_{1}$ is the volume of water chamber plus the volume of the air chamber; $\mathrm{V}_{2}$ is the final volume and $\mathrm{P}_{1}$ is the ambient pressure.

However, the pressure $\mathrm{P}_{2}$ depends of the piston plunger position, because volume $V_{2}$ is the volume of the air chamber plus the volume of the portion of piston without water. Therefore, the equation of $\mathrm{V}_{2}$ can be written as in (5).

$$
V_{2}(x)=V_{c h}+\Pi \times r^{2} \times x
$$

Where: $\mathrm{V}_{\mathrm{ch}}$ is the volume of the air chamber and $\mathrm{x}$ is the position of the piston plunger (between $0 \mathrm{~m}$ and $0.2 \mathrm{~m}$ ).

Therefore, if equation (5) over equation (4) is used, the stored pressure $\left(\mathrm{P}_{\mathrm{ch}}\right)$ depending to $\mathrm{x}, \mathrm{P}_{\mathrm{ch}}(\mathrm{x})$ is obtained. (6).

$$
P_{c h}(x)=P_{1} \frac{V_{c i l}+V_{c h}}{V_{c h}+\Pi \times r^{2} x}
$$

Where: $\mathrm{V}_{\text {cil }}$ is the volume of the water chamber and $\mathrm{V}_{\mathrm{ch}}$ is the volume of the air chamber.

The graph shown in figure 4 is obtained by simulating equation (6). An exponential relation between $P_{c h}$ pressure (the pressure stored in air chamber) and the piston plunger position can be observed. The stored pressure rises exponentially when plunger goes back, because decrease the volume in the piston set. The pressure is highest when $\mathrm{x}=0$ (1.5 liters of water is picked up by the piston and it compress all the air) as can be seen. And the pressure is lowest when 


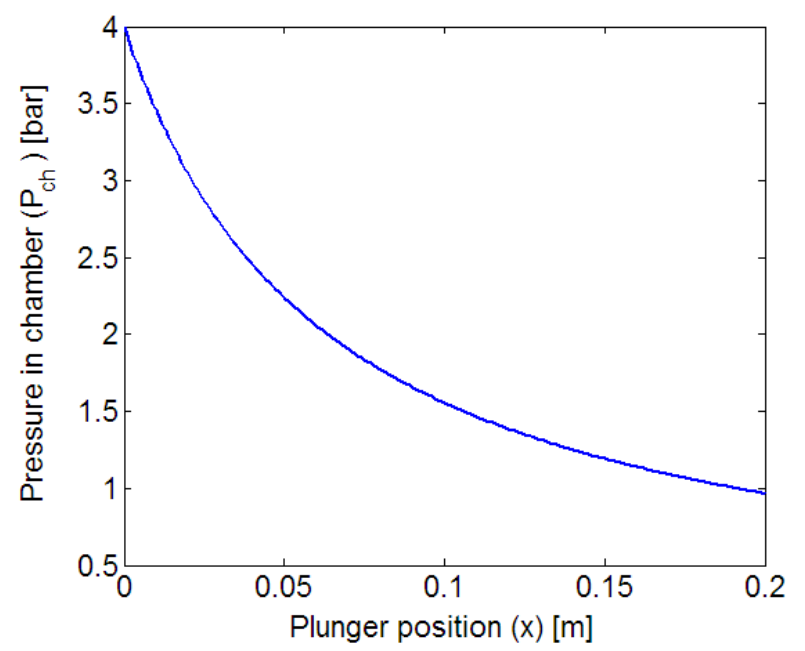

Fig. 4. Shows an exponential relation between $P_{c h}$ pressure (the pressure stored in air chamber) and the piston plunger position (equation (6))

$\mathrm{x}=0.2$. In this case, the pressure is 1 bar the same of the ambient (the piston ejects all the water and the system goes in the equilibrium state).

From this point, the total amount of force that needs the engine of the piston to eject the water has been calculated. This force, as explain in previous sections, is depending of the vehicle depth. However, the force carried out by the engine can be reduced using an air chamber as can be seen in equation (7).

$$
F_{m}=F_{\text {sea }}-F_{c h}+F_{f}
$$

Where: $F_{m}$ is the engine force, $F_{\text {sea }}$ is the force of depth pressure, $F_{c h}$ is the force of the air chamber pressure and $F_{f}$ is the friction force.

Using equation (7), known that Force = Surface $x$ Pressure and assuming that $\mathrm{F}_{\mathrm{ch}}$ depend on $\mathrm{x}$ the force of

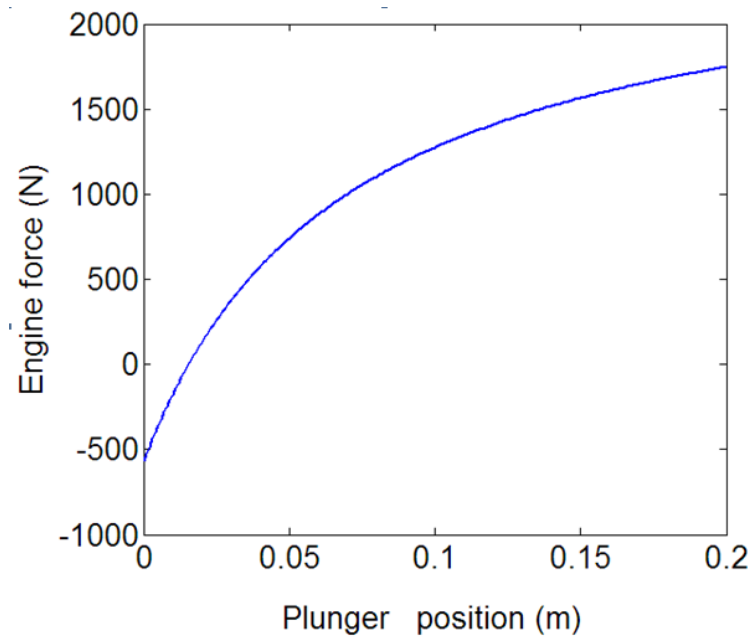

Fig. 5. Shows the engine force versus plunger position (equation 8). Using a $P_{\mathrm{se}}$ of 3 bars. engine in Newton using equation (8) has been obtained.

$$
F_{m}(x)=A\left[P_{\text {sea }}-P_{c h}(x)\right] \times 0.1+F_{f}
$$

Where: $A$ is the surface of plunger in $\mathrm{mm}^{2}, \mathrm{P}_{\text {sea }}$ is the pressure in the depth and 0.1 is the relation between pressure in bar and force in Newton.

The graph of figure 5 is obtained by plotting the equation 8. This graph is calculated using a $P_{\text {sea }}$ pressure of 3 bars. In figure 5 an engine negative force between $0 \mathrm{~m}$ and $0.03 \mathrm{~m}$ can be observe. This happens because the pressure in the air chamber $\left(\mathrm{P}_{\mathrm{ch}}\right)$ is higher than the pressure in the sea $\left(\mathrm{P}_{\text {sea }}\right)$. This have to be corrected because if not would indicate that power is being generated in the engine. Obviously if the pressure in air chamber is higher than water pressure, the engine needs less power than otherwise (when the pressure of air chamber is less than water pressure). However, the engine has always minimum force consumption, due to its construction and operation. After a preliminary test and using equation (3) two static forces has been obtained. The engine-piston force when it works without load (pressure is zero) and when it works with overpressure (the pressure of air chamber is higher than the water pressure). $\mathrm{F}_{0}$ and $\mathrm{F}$ overpressure.

$$
\begin{gathered}
\mathrm{F}_{0}=187 \mathrm{~N} \\
\mathrm{~F}_{\text {overpressure }}=93 \mathrm{~N}
\end{gathered}
$$

$\mathrm{F}_{0}$ is used as forces of different losses and $\mathrm{F}_{\text {overpressure }}$ as a minimum engine force.

Finally, using equations (8), (3) and taking into account the minimum engine consumption explained above, the consumption of the engine versus the position of plunger and its average has been calculated in figure 6 .

Using the same system, the average engine consumption in amperes at different depths has been calculated and simulated. Taking into account three scenarios: without a chamber, with 0.5 liters of air chamber and with 0.25 liters of air chamber.

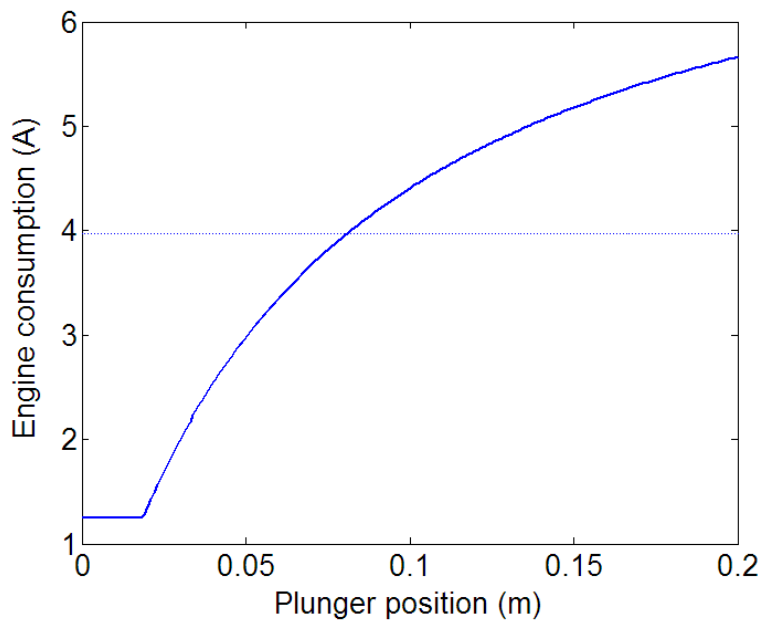

Fig. 6. Shows the engine force and its average (dot line) versus plunger position (equation 8 ) taking into account the minimum engine consumption 


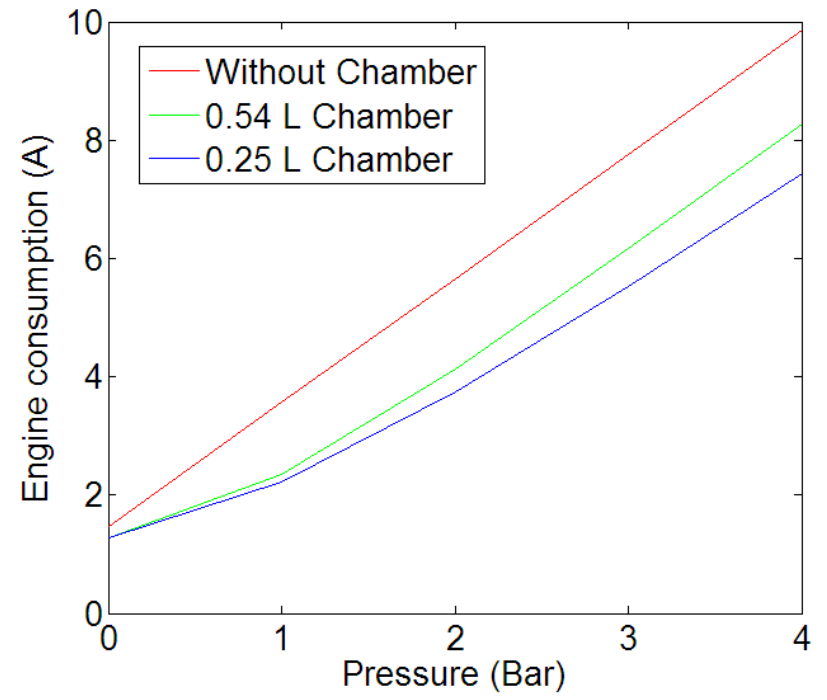

Fig. 7. Shows the average engine consumption in amperes at different depths. Taking into account three scenarios: without a chamber, with 0.5 liters of air chamber and with 0.25 liters of air chamber

Results can be seen in figure 7. The use of an air chamber reduces the total engine consumption in all depths (between 0 $\mathrm{m}$ and $40 \mathrm{~m})$ as can be seen in the simulation. However, the consumption variation in lowest pressures is less than in highest pressures. Furthermore, in the first meters $(0 \mathrm{~m}-10$ $\mathrm{m})$ virtually no difference exists between the use of an air chamber of $0.5 \mathrm{~L}$ or $0.25 \mathrm{~L}$. This is because in this case, increasing the pressure stored in the air chamber not affects positively if there is no equivalent force of pressure on the other end of the piston (the sea end). As discussed above, the engine has always a minimum consumption. But, in highest pressures a reduction of consumption when a smallest air chamber is used can be seen.

The theoretical reduction on consumption can be calculated by figure 7. For example, the engine consumption reduction in the 2 bar case is $1.92 \mathrm{~A}$, when an air chamber of 0.25 liters has been used. This represents a reduction of $33.9 \%$.

In the next section the laboratory tests are shown and discussed to validate the system of variable buoyancy.

\section{LABORATORY TESTS}

Two tests have essentially been performed: first a dry test using an air compressor; secondly, a test was carried out in water into a hyperbaric chamber. These two models have been used to perform a study of the system behavior. All variables such as the current, the voltage and the pressure has been measured using a digital multimeter with GPIB port and monitored using a laptop with a GPIB connection and a LabView software. Figure $8 \mathrm{a}$ and figure $8 \mathrm{~b}$ show the two tests.
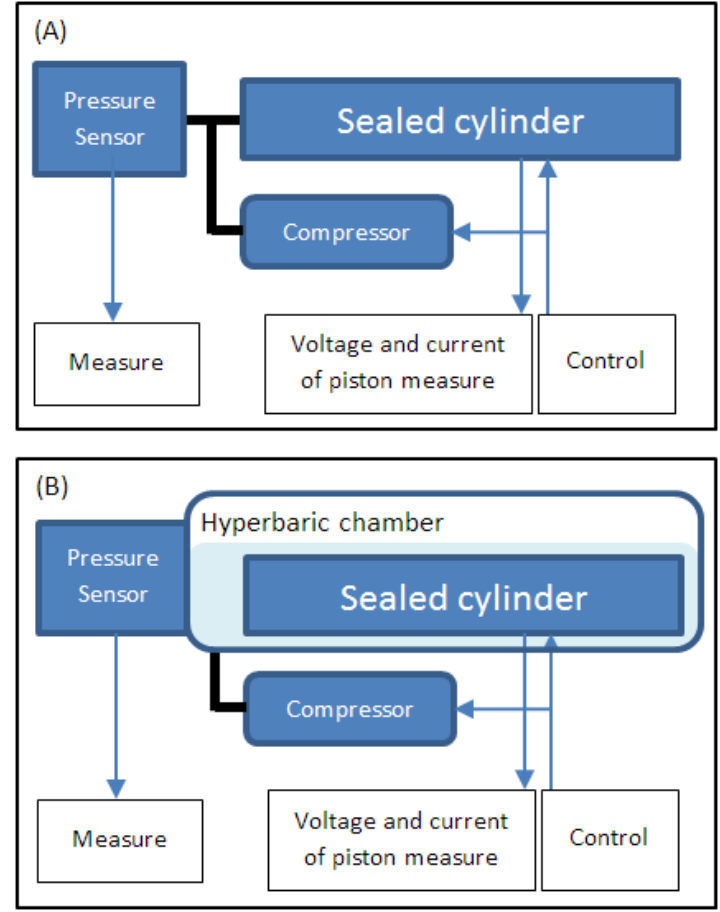

Fig. 8. a) Block diagram of the test bank to perform the analysis in the dry test. b) Block diagram of the test bank to perform the analysis in the water test

\section{A. Dry test:}

As mentioned, the output of piston for this test is connected to an air compressor. By varying the pressure in compressor tank it is possible to simulate the different operating depths. The pressure from 0 bars to 4 bars can be to adjust. In table I a pressure of 4 bars involves a current of $9 \mathrm{~A}$ or more as can be observe. In this case this is a limitation, because the maximum current of the engine specified by manufacturer is $9 \mathrm{~A}$ in a continuous mode. The block diagram of the test bank to perform the analysis is shown in figure 8a. The picture of the test that it was carried out is shown in figure 9 (left).

\section{B. Water test:}

For the water test, the sealed cylinder and enginepiston set have been placed inside a hyperbaric chamber. Thus, the behavior in the sea has been possible to simulate. The measurement setup is similar that described above but with the cylinder inside of a hyperbaric chamber. The effect of the depth is simulated by varying the pressure of hyperbaric chamber. The block diagram of the test bank to perform the analysis is shown in the figure $8 \mathrm{~b}$ and a picture of the test is shown in the figure 9 (right). 

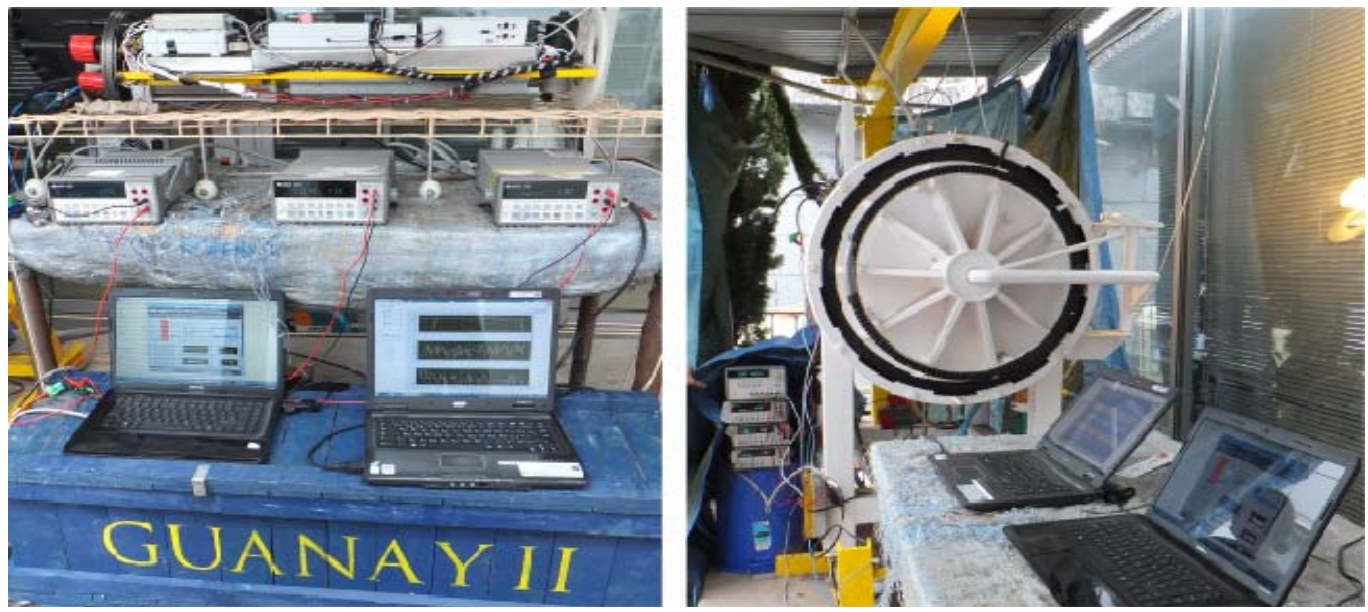

Fig. 9. Left picture: shows the test in dry. Right picture: shows the test in the hyperbaric chamber

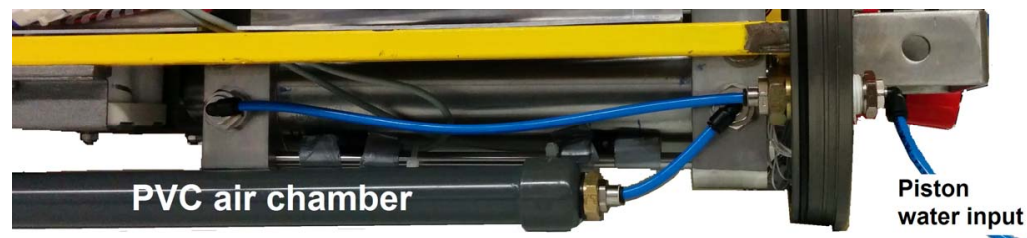

Fig. 10. This picture shows the PVC air chamber connected to the piston to carried out the test

On the other hand, an air chamber has been tested. Once validated the engine-piston system a test has been performed to see the behavior of the new system using an air chamber. In figure 10 a picture of how the test has been performed is shown.

\section{Air chamber test:}

To perform this test, the same idea as in the dry test discussed above has been used. Different consumptions of the engine versus two parameters have been seen in this test. First parameter is the pressure at the sea input. Second parameter is the use of different air chambers connected to the piston as discussed in section 3. Two air chambers, one of 0.54 liters and other of 0.25 liters have been used to validate the system and to validate the equations and simulations performed.

\section{FIELD TESTS}

Finally, the Guanay II buoyancy system has been tested in the field. The main idea was make some immersions in shallow water. Four tests haves been carried out, the first one up to 5 meter and with increments of 5 meters up to 20 meters of depth. The main variables of piston, such as the current and the voltage, in each immersion are monitored. Thus, variable buoyancy system has been validated.

To perform this test part of the OBSEA infrastructure [3] located $4 \mathrm{~km}$ in front of Vilanova i la Geltrú coast (Barcelona) in the Mediterranean Sea has been used. OBSEA is a cabled underwater observatory with up to $3.6 \mathrm{~kW}$ and the high bandwidth communication link of 1 Gbps.

This test was carried out in the OBSEA using one of the planned maintenance dives. The main advantage is the knowledge of the zone and the depth. At this point the maximum depth is 20 meters, a good safety margin for the vehicle. A simulation of the test in OBSEA is shown in figure 11.

In future works Guanay II will be able to use OBSEA as

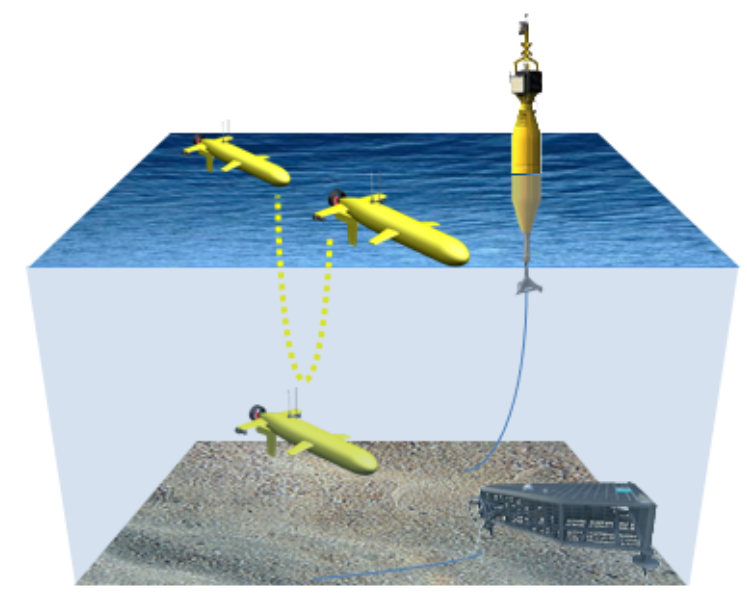

Fig. 11. Shows a simulation of the test in OBSEA 
an access point to send information to land station and it can be used to perform some tasks of maintenance and surveillance.

Finally, the compensation system of the piston has been only preliminarily tested in the laboratory.

\section{RESULTS}

Two types of results have been obtained. The results from laboratory and the results from field test. The first one, the variable buoyancy system has been tested in a controlled environment to know their behavior. Then, a field test has been carried out to see their behavior in a real environment.

In the laboratory the power of the engine-piston set without air chamber test has been monitored. In the following figure the relationship between the pressure and current drawn by the engine-piston set is shown (figure 12). The dry test, the water test and the manufacturer's specifications has been compared.

The maximum power of the engine to move the piston is 9 A, as can be seen in the manufacturer datasheet. This limits the maximum depth that the vehicle can down. The maximum depth is less than 40 meters as can be seen in figure 12 .

After obtaining the results of the laboratory tests and observes the proper function of the system, the air chamber test has been performed. Figure 13 shows the results are obtained. Where the average currents drawn by the engine in the action of eject the water of inside of the piston at different depths and with different air chambers have been compared.

The consumption of engine when an air chamber is used is smaller than if not used as can be seen in figure 13. This air

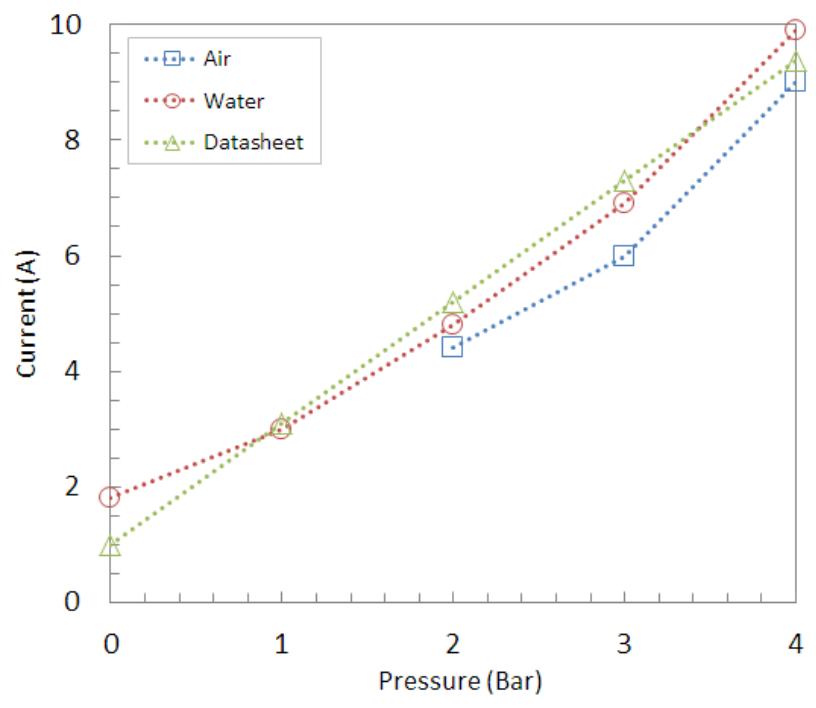

Fig. 12. Piston current vs. Pressure (in air, water and datasheet). Laboratory tests.

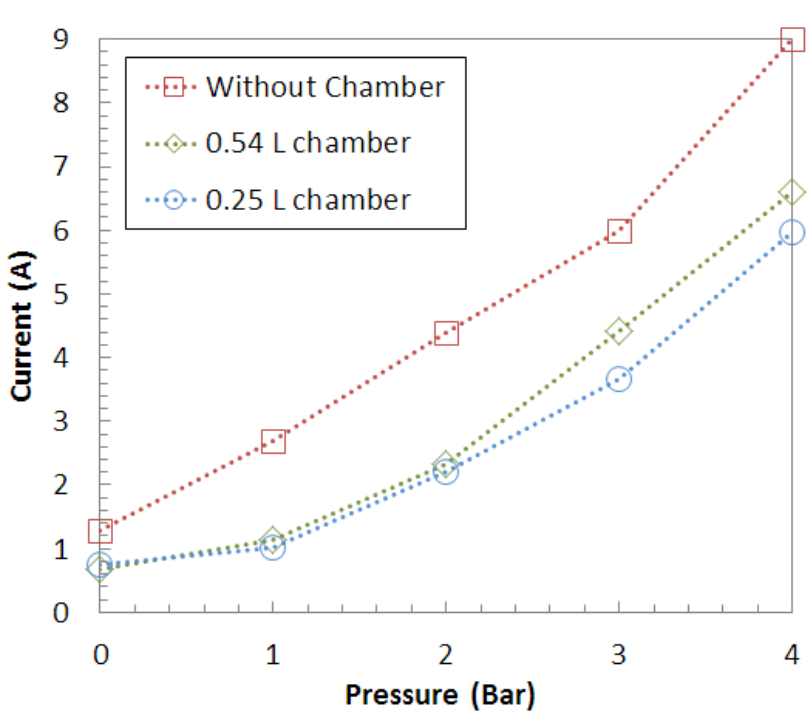

Fig. 13. Piston current vs. pressure (Without air chamber, with 0.54 liters of air chamber and with 0.25 liters of air chamber. Laboratory tests.

chamber previously has been used to compress air and then to aid the engine in the process of eject the water. These experimental results shows the same behaviors that can be seen in the simulations (see figure 7). At low pressures, the decreases in the volume of air chamber not reflect decreases in consumption of the engine. This is because the engine-piston system has a minimum consumption.

The real reduction in the consumption can be calculated by figure 13. For example, the engine consumption reduction in the 2 bar case is $2 \mathrm{~A}$, when an air chamber of 0.25 liters has been used. This represents a reduction of $45.4 \%$. This result is similar to that obtained in the simulations. However, there are a small mismatch between the simulation and the field test. This mismatch is basically an offset between the field test and the simulations.

Finally, the results from field test in the OBSEA are shown. In figure 14 a representation of different immersions at different depths $(5 \mathrm{~m}, 10 \mathrm{~m}, 15 \mathrm{~m}$ and $20 \mathrm{~m})$ over the time has been shown. In addition, a color bar has been introduced to represent the temperature of the water. To collect this data a Conductivity, Temperature and Depth (CTD) sensor has been used. The water temperature varies around $2^{\circ} \mathrm{C}$ between surface and 20 meters of depth as can be seen. This test validates the Guanay II variable buoyancy system in a real environment.

\section{CONCLUSIONS}

A study of variable buoyancy system has been carried out. Then a laboratory tests has been performed. Finally, a real field test has been accomplished, obtaining a good performance in booth tests. On the other hand, a new system 


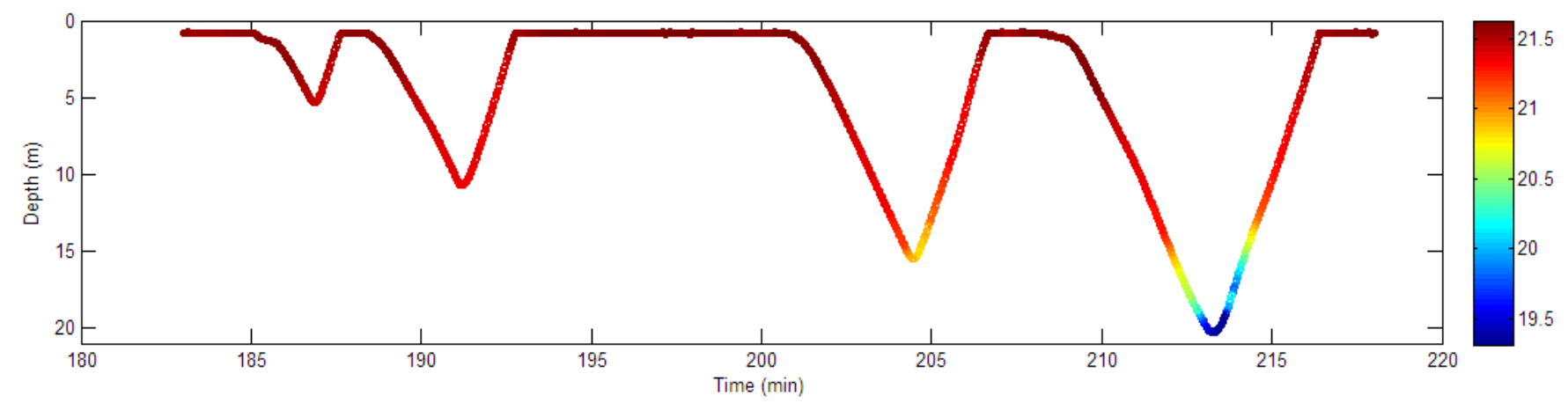

Fig. 14. Dives carried out during the field tests in OBSEA. The dives at $5 \mathrm{~m}, 10 \mathrm{~m}, 15 \mathrm{~m}$ and $20 \mathrm{~m}$ can be seen. The temperature of water in the different depths is represented in color. OBSEA test.

with an air chamber has been studied, obtaining a good performance in the tests. A reduction of around $45 \%$ of the energy to go up has been obtained. This implies an increase in the security of the vehicle.

\section{ACKNOWLEDGMENT}

This work has been funded by the Spanish Ministry of Education and Science and the European Union (FEDER), project $\mathrm{n}^{\circ}$ : CTM2009-08867.

\section{REFERENCES}

[1] I. Masmitja, G. Masmitja, J. González, S. Shariat-Pahani, S. Gomáriz, "Development of a control system for an autonomous underwater vehicle". OES-IEEE AUV'10. Septiembre 2010. Monterey, California.

[2] Gomariz, S.; Masmitja, I.; González, J.; Masmitjà, G.; Prats, J. "Guanay-II: an autonomous underwater vehicle for vertical/horizontal sampling". Journal of marine science and technology. 2014. ISSN: 0948-4280. DOI 10.1007/s00773-013-0253-y

[3] Nogueras, M.; del Rio, J.; Cadena, J.; Sorribas, J.; Artero, C.; Danobeitia, J.; Manuel, A. "OBSEA an oceanographic seafloor observatory" Industrial Electronics (ISIE), 2010 IEEE International symposium. 2010, pages: 488-492.

[4] S. Gomáriz, J. González, A. Arbos, I. Masmitja, G. Masmitja, J. Prat. "Design and construction of the Guanay-II Autonomous Underwater Vehicle". Oceans 2011 IEEE/OES. Santander, Spain. June 2011.

[5] S. Gomáriz, J. Prat, A. Arbos, O. Pallares, and C. Viñolo, "Autonomous vehicle development for vertical submarine observation" in International Workshop on Marine Technology, (Vilanova i la Geltrú, Spain), november 2009.

[6] S. Gomáriz, J. Prat, P. Gayà, and J. del Río, "Development of low-cost autonomous oceanographic observation vehicle", in Oceans'09 MTS/IEEE, (Brement, Germany), may 2009.

[7] Ribas, D.; Ridao, P.; Magi, L.; Palomeras, N.; Carreras, M. "The Girona 500, a multipurpose autonomous underwater vehicle", OCEANS, 2011 IEEE - Spain. 10.1109/Oceans-Spain.2011.6003395

[8] Bellingham, J.G. ; Yanwu Zhang ; Kerwin, J.E. ; Erikson, J. ;Hobson, B. ; Kieft, B. ; Godin, M. ; McEwen, R. ; Hoover, T. ;Paul, J. ; Hamilton, A. ; Franklin, J. ; Banka, A. " Efficient propulsión for the Tetys long-range autonomous underwater vehicle" Autonomous

$\begin{array}{lcccc}\text { Underwater } & \text { Vehicles } & \text { (AUV), } & 2010 & \text { IEEE/OES. } \\ \text { 10.1109/AUV.2010.5779645 } & & & \end{array}$

[9] Min Xu, S.M. Smith "Adaptive Fuzzy Logic Depth Controller for Variable Buoyancy System of Autonomous Underwater Vehicles" Fuzzy Systems, 1994. IEEE World Congress on Computational Inteligence. 10.1109/FUZZY.1994.343904 